\title{
Michael Additions Catalyzed by Bifunctional Mesoporous Silica
}<smiles>CC(=O)CC(C)=O</smiles>

6 (1.6 mol equiv)

$1083 \%$ yield
Significance: The Michael reaction mediated by mesoporous silica-supported amine-urea bifunctional catalysts is reported in which the tertiary amine and the urea moieties work as a base and an acid, respectively. The reaction of acetylacetone (6) with 2-nitrostyrene (7) was carried out with bifunctional catalyst 1 (amine/urea $=53: 47$ ) under conditions A to give 3-[1-(1-phenyl-2-nitroethyl)]-2,4-pentadione (8) in $80 \%$ yield. When catalysts 2-5 were used, product $\mathbf{8}$ was obtained in 0-56\% yield. Catalyst 1 was reused three times under conditions B to afford product $\mathbf{8}$ in high yields.
Comment: The reaction of Cbz-benzaldimine (9) and $\mathbf{6}$ with catalyst $\mathbf{1}$ in toluene was also performed to afford product $\mathbf{1 0}$ in 83\% yield. Catalysts 1-5 were prepared in accordance to the previously reported procedure (V. S.-Y. Lin and coworkers Angew. Chem. Int. Ed. 2005, 44, 1826). Enantioselective Michael addition of malonates to nitroolefins using bifunctional organocatalysts was reported by Takemoto and co-workers (J. Am. Chem. Soc. 2003, 125, 12672). 